\title{
Saliva, supragingival biofilm and root canals can harbor gene associated with resistance to lactamic agents
}

\section{Ludmila Coutinho MORAES(a) Clarissa Cavalcanti FATTURI-PAROLO(b) Maria Beatriz Cardoso FERREIRA(c) Marcus Vinicius Reis SÓ(a) Francisco MONTAGNER(a)}

(a) Universidade Federal do Rio Grande do Sul - UFRGS, School of Dentistry, Department of Conservative Dentistry, Porto Alegre, RS, Brazil.

(b) Universidade Federal do Rio Grande do Sul - UFRGS, Cariology Division, Department of Preventive and Social Dentistry, Porto Alegre, RS, Brazil.

(c) Universidade Federal do Rio Grande do Sul - UFRGS, Basic Health Science Institute, Department of Pharmacology, Porto Alegre, RS, Brazil.

Declaration of Interests: The authors certify that they have no commercial or associative interest that represents a conflict of interest in connection with the manuscript.

Corresponding Author:

Francisco Montagner

E-mail: francisco.montagner@ufrgs.br

DOI: 10.1590/1807-3107BOR-2015.vol29.0052

Submitted: Oct 06, 2014

Accepted for publication: Jan 02, 2015

Last revision: Feb 12, 2015

\begin{abstract}
This study aimed to determine the presence of Prevotella strains and genes associated with resistance to lactamics in different oral niches from patients with/without primary endodontic infections. Saliva (S) and supragingival biofilm (SB) were collected from three patient groups: Group I - no endodontic infection $(\mathrm{n}=15)$; Group II - acute endodontic infection ( $\mathrm{n}=12)$; and Group III - chronic endodontic infection $(n=15)$. Root canal $(R C)$ samples were collected from Groups II and III. The presence of $P$. intermedia, $P$ nigrescens, $P$. tannerae and $c f x A / c f x A 2$ gene was assessed by PCR. The $c f x A / c f x A 2$ gene was not detected in all environments within the same patient. The $c f x A / c f x A 2$ gene was present in $23.81 \%$ of $S$ samples, $28.57 \%$ of $S B$ samples, and $7.41 \%$ of RC samples. Prevotella species were detected in $53.97 \%, 47.62 \%$ and $34.56 \%$ of the S, SB, and RC samples, respectively. $P$. intermedia had a high frequency in saliva samples from Group 3. Saliva samples from Group 1 had higher detection rates of P. nigrescens than did Groups 2 and 3. Patients without endodontic disease had high frequencies of $P$. nigrescens in the SB samples. The presence or absence of spontaneous symptoms was not related to the detection rates for resistance genes in the RC samples. Saliva, supragingival biofilm and root canals can harbor resistant bacteria. The presence of symptomatology did not increase the presence of the $c f x A / c f x A 2$ gene in the supragingival biofilm and inside root canals.
\end{abstract}

Keywords: Drug Resistance; Mouth; Endodontics; Molecular Biology.

\section{Introduction}

In endodontics, antimicrobial agents are used as a complementary measure for the control of acute infections. Among these agents, beta-lactam drugs are safer, but certain classes have specific adverse effects. ${ }^{1}$ The over- and misuse of antibiotics can promote the selection of resistant pathogens and allow their emergence and dissemination. ${ }^{2}$ The most efficient mechanism of resistance to beta-lactam antibiotics is enzyme production. ${ }^{3}$ The isolation of beta-lactamase-producing strains has rapidly increased due to intra- and inter-species genetic transmission. ${ }^{4}$ The production of beta-lactamase enzymes is encoded by the chromosomal genes $c f l I A$ and $c f x A / c f x A 2$. The $c f x A / c f x A 2$ gene was cloned from a strain of Prevotella intermedia that had been isolated from the oral cavity and exhibited $98 \%$ similarity to the sequence originally 
described for the $c f x A$ gene in Bacteroides vulgatus. ${ }^{4}$ The $c f x A / c f x A 2$ gene is associated with the degradation of beta-lactamics, especially by black-pigmented bacilli, such as Prevotella spp. ${ }^{5}$

Recent studies have investigated the presence of genes exhibiting bacterial resistance to antibiotics, including the $c f x A / c f x A 2$ gene, in clinical samples from endodontic infections. ${ }^{6,7,8}$ However, no report has investigated the presence of these genes in oral cavity sites, such as the supragingival plaque, which is an important source of microorganisms for endodontic infections. This study aimed to identify the presence of microorganisms and virulence factors associated with antimicrobial resistance in samples from different niches of the oral cavity in different clinical situations.

\section{Methodology}

The present research was approved by the Ethics Committee in Research (protocol number, CAE 08375712.1.0000.5347) from the Universidade Federal do Rio Grande do Sul - UFRGS (Porto Alegre, RS, Brazil). Forty-two subjects ( $>18$ years old) attending the Urgency Service at the Dental Clinics (Dental School, UFRGS, Porto Alegre, Brazil) were selected for the present study. Before participating, patients were asked to provide informed consent. None of the patients were excluded if they had received antibiotic treatment during the preceding 3 months. Patients with systemic disease or teeth with periodontal probing depth greater than $4 \mathrm{~mm}$ were also not included. No included patients wore total or partial dentures.

These patients were divided into three groups according to the following criteria: Group I - absence of root canal infection ( $n=15)$; Group II - presence of acute root canal infection ( $\mathrm{n}=12)$; and Group III presence of chronic root canal infection $(n=15)$. Saliva samples (S) and supragingival biofilm (SB) were collected from all patients. Root canal samples (RC) were collected for Groups II and III. Sample size was determined based on previous results reported by Gomes et al. ${ }^{9}$ (frequency of the species) and according to Jungermann et al. ${ }^{6}$ (frequency of detecting the $c f x A / c f x A 2$ gene).

\section{Sampling procedure}

The non-stimulated saliva was collected in a sterile Eppendorf tube..$^{10}$ The supragingival biofilm was collected randomly at 15 sites using sterile microbrushes (Dentsply Caulk, Milford, USA). The tip of each brush was cut, and the biofilms were immediately placed in sterile Eppendorf tubes. ${ }^{9}$ Root canal samples were collected as described by Montagner et al. ${ }^{11,12}$ Coronal caries and defective restorations were removed. The involved tooth was isolated. Control samples were taken from both the external tooth surface and operative field after disinfection. The operative field disinfection was performed with $30 \%$ hydrogen peroxide and $5.25 \%$ sodium hypochlorite, followed by neutralization with $5 \%$ sodium thiosulfate. The canals were exposed under manual irrigation (sterile saline solution) using sterile burs. The paper points were introduced near the total length of the root canal according to the preoperative radiographs. The joints were kept in position for $1 \mathrm{~min}$. If the canals were dry, they were moistened with sterile saline. The paper points were then introduced into tubes. All samples were stored at $-20^{\circ} \mathrm{C}$.

\section{Detection of the Prevotella species and cfxA/cfxA2 gene using PCR}

The DNA was isolated with a QIAamp DNA Minikit (Qiagen, Valencia, USA) according to the manufacturer's instructions. The DNA from all saliva, supragingival biofilm and root canal samples was first amplified with universal prokaryotic ribosomal 16S primer $^{13}$ (forward: TCCTACGGGAGGCAGCAG, and reverse: GGACTACCAGGGTATCTAATCCTGTT).

The PCR amplification was used to detect the species Prevotella intermedia, P. nigrescens and P. tannerae. Species-specific primers were used that were targeted to the region of the $16 \mathrm{~S}$ rRNA gene in bacterial DNA. The sequences of the oligonucleotides $\left(5^{\prime}-3^{\prime}\right)$ were obtained from the literature: P.intermedia: ${ }^{14}$ forward: TTTGTTGGGGAGTAAAGCGGG, and reverse: TCAACATCTCTGTATCCTGCGT; $P$. nigrescens: ${ }^{15}$ forward: ATGAAACAAAGGTTTTCCGGTAAG, and reverse: CCCACGTCTCTGTGGGCTGCGA; and P. Tannerae: ${ }^{16}$ forward: CTTAGCTTGCTAAGTATGCCG, and reverse: CAGCTGACTTATACTCCCG. 
PCR reactions were processed in $10 \mu \mathrm{l}$ for each sample: $8 \mu$ l containing Taq PCR Master Mix Kit (Qiagen, Valencia, USA), $0.5 \mu$ of a solution of $10 \mu \mathrm{M}$ forward primer (Invitrogen, Sao Paulo, Brazil), $0.5 \mu \mathrm{l}$ of a $10 \mu \mathrm{M}$ reverse primer solution (Invitrogen, Sao Paulo, Brazil), and $1 \mu \mathrm{l}$ of DNA extracted from clinical samples.

The steps of the PCR cycle comprised an initial denaturation $\left(95^{\circ} \mathrm{C}, 2 \mathrm{~min}\right), 33-36$ cycles of denaturation $\left(94^{\circ} \mathrm{C}, 30 \mathrm{~s}\right)$, annealing (temperature specific for each primer set, $1 \mathrm{~min})$ and extension $\left(72^{\circ} \mathrm{C}, 2 \mathrm{~min}\right)$, followed by a final extension $\left(72^{\circ} \mathrm{C}, 10 \mathrm{~min}\right)$.

Aliquots of bacterial DNA extracted from strains (P. intermedia ATCC 25611, P. nigrescens ATCC 33563, and P. tannerae ATCC 51259) and aliquots of ultrapure water were used as positive and negative controls, respectively.

PCR was also used to detect the presence of the $c f x A / c f x A 2$ gene according to the protocol described by Giraud-Morin et al. ${ }^{17}$ As a positive control, the Bacteroides vulgatus CLA 341 strain was used. PCR reactions were processed in $10 \mu$ for each sample: $8.6 \mu \mathrm{l}$ of Taq PCR Master Mix Kit (Qiagen, Valencia, USA), $0.2 \mu 1$ of each $c f x A / c f x A 2$ primer $(10 \mu \mathrm{M})$ : forward GAAAAAAACAGAAAAAAACAAATC, reverse: TTAAGATTTTACTGAAGTTTG, and $1 \mu \mathrm{l}$ of microbial DNA.

The PCR reaction steps were as follows: initial denaturation $\left(94^{\circ} \mathrm{C} ; 5 \mathrm{~min}\right) ; 25$ cycles of denaturation $\left(94^{\circ} \mathrm{C}, 1 \mathrm{~min}\right)$; annealing $\left(58^{\circ} \mathrm{C}, 1 \mathrm{~min}\right)$; extension $\left(72^{\circ} \mathrm{C}\right.$, $30 \mathrm{~s})$; and a final extension $\left(72^{\circ} \mathrm{C}, 10 \mathrm{~min}\right)$.

The presence of specific amplicons in each sample was verified by gel electrophoresis in $1 \%$ agarose (Invitrogen, Sao Paulo, Brazil) and staining (Sybr Green, Applied Biosystems, Sao Paulo, Brazil). Positive reactions were determined by the presence of bands with the proper length visualized under ultraviolet transillumination.

\section{Data Analysis}

The data (clinical features and gene detected) were entered into a spreadsheet and analyzed (SPSS for Windows, SPSS Inc., Chicago, USA). The Pearson Chi-square test was used to assess differences in the detection of specific genes in the same oral environment (S, SB or RC) and in different groups.
The Cochran's Q Test was used to assess differences in the detection of a specific gene in the same group but in different oral environments (S, SB or RC). Significance was defined as $5 \%$.

\section{Results}

The mean age of the patients was 38.7 years (range, 19-69 years). Fifty-two percent of the patients were female. All patients in Group II reported a history of spontaneous pain, and Group III patients had asymptomatic apical lesions without the presence of sinus tracts. RCs of 17 incisors, 1 canine, 3 premolars, and 6 molars were sampled. Gingivitis was associated with 16/27 teeth. Thirty-three percent of the teeth belonging to Group II had mobility. Thirty-three percent of the teeth from Group III had fistula. Radiographic examination showed widening of the apical periodontal ligament space for $25 \%$ and $13 \%$ and apical radiolucency for $58 \%$ and $86 \%$ of patients in Groups II and III, respectively.

All S, SB and RC samples were positive results for the presence of bacteria as determined by universal $16 S$ rRNA gene-base PCR. No control samples were positive presence of bacterial DNA. All three species of Prevotella were present in $53.97 \%$ of S samples, in $47.62 \%$ of $S B$ and $34.56 \%$ of the RC samples. The overall rate detection of the $c f x A / c f x A 2$ gene was $23.81 \%$ in the saliva samples; $28.57 \%$ in the supragingival biofilm samples, and $7.41 \%$ in the root canal. The $c f x A / c f x A 2$ gene was not detected in the S, SB and RC of the same patient. However, the $c f x A / c f x A 2$ gene was present in the saliva and supragingival samples of five patients. Only one patient (1/27) harbored the cfxA/A2 gene in their SB and RC samples. Table 1 shows the detection rates for each Prevotella species and the $c f x A / A 2$ gene in the groups considering the different oral environments (saliva, supragingival biofilm and root canal samples).

In Group I, the selected patients did not have acute or chronic primary endodontic infections at the time of collection. These patients presented to the Urgency Service for other reasons, such as dental caries, dental trauma or pulpitis. Only $S$ and SB samples were analyzed. Prevotella species were frequently detected in both the saliva and supragingival biofilm samples (P. intermedia: $S=73.33 \%$; 
Table 1. Frequency and percentage of each Prevotella species and cfxA/A2 gene in the collected samples.

\begin{tabular}{|c|c|c|c|c|c|c|c|c|c|}
\hline & \multicolumn{3}{|c|}{ Saliva } & \multicolumn{3}{|c|}{ Supra-gingival Biofilm } & \multicolumn{3}{|c|}{ Root Canal } \\
\hline & $\mathrm{Gl}(\mathrm{n}=15)$ & $\mathrm{G} 2(\mathrm{n}=12)$ & $\mathrm{G} 3(\mathrm{n}=15)$ & $\mathrm{Gl}(\mathrm{n}=15)$ & $\mathrm{G} 2(\mathrm{n}=12)$ & $\mathrm{G} 3(\mathrm{n}=15)$ & $\mathrm{Gl}(\mathrm{n}=15)$ & $\mathrm{G} 2(\mathrm{n}=12)$ & $\mathrm{G} 3(\mathrm{n}=15)$ \\
\hline & Absence $\mathrm{El}$ & Acute El & Chronic El & Absence $\mathrm{El}$ & Acute El & Chronic El & Absence El & Acute El & Chronic El \\
\hline P. intermedia & $11(73.3 \%)^{a}$ & $4(33.3 \%)^{a, A}$ & $13(86.6 \%)^{a}$ & $11(73.3 \%)$ & $4(33.3 \%)^{A}$ & 8 (53.3\%) & - & $5(41.6 \%)^{\mathrm{A}}$ & $8(53.3 \%)$ \\
\hline P. nigrescens & $7(46.6 \%)^{b}$ & $0(0 \%)^{b}$ & $1(6,6 \%)^{b}$ & $9(60 \%)^{c}$ & $1(8.3 \%)^{c}$ & $0(0 \%)^{c}$ & - & $1(8.3 \%)$ & 2 (13.3\%) \\
\hline P. tannerae & $11(73.3 \%)$ & $11(91.6 \%)$ & $10(66.6 \%)$ & $10(66.6 \%)$ & $8(66.6 \%)$ & 9 (60\%) & - & $5(41.6 \%)$ & 7 (46.6\%) \\
\hline$c f x A / c f x A 2$ gene & $2(13.3 \%)$ & 4 (33.3) & $4(26.6 \%)$ & $4(26.6 \%)$ & $6(50 \%)$ & $2(26.6 \%)$ & - & $2(16.6 \%)$ & $0(0 \%)$ \\
\hline
\end{tabular}

* El = Endodontic Infection; Small letters indicate statistical significance difference for the presence of the same species, in the same environment, for different test groups (Pearson Chi-square test, $p<0.05$ ); Capital letters indicate statistical significance difference for the presence of the same species, in the same group, for different environments (Cochran $Q$ test, $p<0.05$ )

$\mathrm{SB}=73.33 \%$; P. nigrescens: $\mathrm{S}=46.67 \%, \mathrm{SB}=60 \%$; and P. tannerae $\mathrm{S}=73.33 \% ; \mathrm{SB}=66.67 \%) . c f x A / c f x A 2$ gene was detected in $13.33 \%$ of saliva samples and $26.67 \%$ of supragingival biofilm. No significant differences in the detection of the same species or the resistance gene were observed in the saliva and supragingival biofilm from Group I participants (Cochran's Q Test, $p>$.05)

In the samples collected from patients with acute primary endodontic infections (Group II), P. tannerae was frequently detected in $S$ samples $(91.67 \%)$, whereas P. nigrescens was not detected in any sample from this environment. Significant differences were observed in the detection of $P$. intermedia among S, SB and RC samples (Cochran's Q Test, $\mathrm{p}=.048$ ). In the supragingival biofilm, the $c f x A / c f x A 2$ gene was detected in $50 \%$ of the samples.

In the samples collected from patient with chronic primary endodontic infections, $P$. intermedia was present in 13/15 saliva samples. No sample was positive for the presence of $P$. nigrescens or the $c f x A / c f x A 2$ gene in SB and RC samples, respectively. $P$. intermedia and $P$. tannerae were simultaneously present in the S, SB and RC samples of $3 / 15$ patients. No significant differences in the detection of the same species or the resistance gene were observed among the saliva, supragingival biofilm and root canal Group III participants (Cochran's Q Test, $\mathrm{p}>$.05).

A positive association was observed for the presence of $P$. nigrescens in saliva, considering the presence of an acute or chronic endodontic infection (Pearson Chi-square test, $\mathrm{p}=.003$ ). The frequency of $P$. nigrescens presence was higher in the control group, followed by the saliva samples collected from participants with chronic and then acute primary endodontic infections.

P. nigrescens was most frequently detected in the supragingival biofilm from participants without primary endodontic disease compared with participants with acute or chronic root canal infections (Pearson Chi-square Test, $\mathrm{p}=.000$ ).

The presence or absence of spontaneous symptoms did not influence the detection rates for the targeted species and the $c f x A / A 2$ gene in the RC samples (Fisher's exact test, $\mathrm{p}>$.05). No significant differences were observed in the detection of $P$. intermedia, $P$. nigrescens, $P$. tannerae and the $c f x A / A 2$ gene in root canal samples collected from Group II and Group III participants.

\section{Discussion}

The present study assessed the prevalence of $P$. intermedia, $P$. nigrescens and $P$. tannerae in saliva, supragingival biofilm and root canals samples from patients with acute and chronic primary infections. The overall detection rates for P. intermedia, P. nigrescens and P. tannerae were $66 \%$, $19 \%$ and $76 \%$ of the saliva samples, respectively. In the supragingival biofilm samples, $P$. intermedia, P. nigrescens and P. tannerae were found in 54\%, $23.81 \%$, and $64 \%$ of the samples, respectively. He et al. ${ }^{18}$ evaluated matched samples from saliva and supragingival and biofilms in Chinese adults without periodontal disease and observed that 
$83.3 \%$ and $70.8 \%$ of the saliva and supragingival samples, respectively, harbored $P$. intermedia.

The presence or absence of an infection in the root canal system did not affect the detection of some species in saliva or supragingival biofilm. Similar frequencies of $P$. tannerae were observed in saliva samples for all patient groups. P. intermedia, $P$. tannerae and $c f x A / c f x A 2$ detection rates in the supragingival biofilm were not affected by the presence/absence of an endodontic infection. Unique behavior was observed for the $P$. nigrescens. Comparing the detection rates of $P$. nigrescens among the patient groups, this microorganism was most frequently detected in saliva and supragingival biofilms from subjects without acute/chronic primary endodontic infections. Teles et al. ${ }^{19}$ suggested that Prevotella nigrescens had increased detection rates in supragingival biofilms collected from healthy patients with no periodontitis, especially after a 7 day period without oral hygiene.

According to Fosse et al., ${ }^{20}$ Prevotella are the main beta-lactamase-producing species in odontogenic infections. Beta-lactamase production is encoded by chromosomal genes, such as $c f x A / c f x A 2, c b l A, c e p A$, and $c f i A$. P. intermedia carry $c f x A / c f x A 2$ genes, and their presence is primarily related to the origin of the strains. ${ }^{19}$ Handal et al.${ }^{21}$ demonstrated the occurrence of $c f x A / c f x A 2$ genes in $100 \%$ of beta-lactam-positive Prevotella strains from American and Norwegian patients with periodontal diseases.

The oral environment appeared to be a reservoir for $c f x A / c f x A 2$-positive bacteria. In the present study, 18/42 (42.86\%) of the patients harbored the $c f x A / c f x A 2$ gene. However, it should be emphasized that it is important to not only describe the presence of the resistance gene but also determine whether the bacteria are functionally resistant to antibiotics. No patient exhibited positive simultaneous detection of the $c f x A / c f x A 2$ in his or her saliva, supragingival plaque and root canal samples. In

\section{References}

1. Owens RC. An overview of harms associated with $\beta$-lactam antimicrobials: where do the carbapenems fit in? Crit Care. 2008;12 Suppl 4:S3. the present study, the targeted gene was detected in both the saliva and supragingival biofilm samples from all the groups. There are no reports regarding the frequency of $c f x A / c f x A 2$ only in saliva samples. In the present study, the overall detection rate for the targeted gene was $23.81 \%$. According to the literature, the detection rates of $c f x A / c f x A 2$ in root canals samples from teeth with acute primary infections range from $0 \%$ to $17 \% .5,6,7$ In the present study, only root canal samples from acute endodontic infections had the $c f x A / c f x A 2$ gene ( $16.7 \%$ of the samples). No root canal samples from chronic primary endodontic infections had the resistance gene. Supragingival biofilm had a higher number of $c f x A / c f x A 2$-positive samples than saliva and root canal samples, as observed in the samples obtained from patients with teeth presenting acute primary endodontic infections.

Oral environments have heterogeneous characteristics (nutrients, oxygen availability, $\mathrm{pH}$ ) and may exert selective pressure, ${ }^{22}$ producing different bacterial community profiles and species selection, influencing also the presence of specific virulence factors, such as resistance genes.

\section{Conclusion}

Different oral niches can be a source of beta-lactamase resistant bacteria. Local conditions, such as the presence of symptomatology, were not related to an increased presence of the $c f x A$ gene in the supragingival biofilm and inside root canals.

\section{Acknowledgements}

This study was supported by a grant from the Fundação de Apoio à Pesquisa do Estado do Rio Grande do Sul (ARD-FAPERGS n. 140112-0). We also thank C. Jeffrey Smith, Department of Microbiology and Immunology, East Carolina University, who kindly provided Bacteroides vulgatus CLA-341.

2. Meyer E, Gastmeier P, Deja M, Schwab F. Antibiotic consumption and resistance: data from Europe and Germany. Int J Med Microbiol. 2013 Aug;303(6-7):388-95. 
3. Chambers HF, Sander MA. Antimicrobial agents - The aminoglycosides. In: Goodman LS, Limbird LE, Milinoff PB, Gilman AG, Hardman JG, editors. Goodman and Gilman's The Pharmacological Basis of Therapeutics. 9th ed. New York: McGraw-Hill; 1996. p. 1103-1121.

4. Geddes AM, Klugman KP, Rolinson GN. Introduction: historical perspective and development of amoxicillin/clavulanate. Int J Antimicrob Agents. 2007 Dec;30 Suppl 2:S109-12.

5. Madinier I, Fosse T, Giudicelli J, Labia R. Cloning and biochemical characterization of a class A beta-lactamase from Prevotella intermedia. Antimicrob Agents Chemother. 2001 Aug;45(8):2386-9.

6. Jungermann GB, Burns K, Nandakumar R, Tolba M, Venezia RA, Fouad AF. Antibiotic resistance in primary and persistent endodontic infections. J Endod. 2011 Oct;37(10):1337-44.

7. Rôças IN, Siqueira Junior JF. Antibiotic resistance genes in anaerobic bacteria isolated from primary dental root canal infections. Anaerobe. 2012 Dec;18(6):576-80.

8. Rôças IN, Siqueira Junior JF. Detection of antibiotic resistance genes in samples from acute and chronic endodontic infections and after treatment. Arch Oral Biol. 2013 Sep;58(9):1123-8.

9. Gomes BP, Jacinto RC, Pinheiro ET, Sousa EL, Zaia AA, Ferraz CC, et al. Porphyromonas gingivalis, Porphyromonas endodontalis, Prevotella intermedia and Prevotella nigrescens in endodontic lesions detected by culture and PCR. Oral Microbiol Immunol. 2005 Aug;20(4):211-5.

10. Papapostolou A, Kroffke B, Tatakis DN, Nagaraja HN, Kumar PS. Contribution of host genotype to the composition of health-associated supragingival and subgingival microbiomes. J Clin Periodontol. 2011 Jun;38(6):517-24.

11. Montagner F, Gomes BP, Kumar PS. Molecular fingerprinting reveals the presence of unique communities associated with paired samples of root canals and acute apical abscesses. J Endod. 2010 Sep;36(9):1475-9.

12. Montagner F, Jacinto RC, Signoretti FG, Sanches PF, Gomes BP. Clustering behavior in microbial communities from acute endodontic infections. J Endod. 2012 Feb;38(2):158-62.
13. Nadkarni MA, Martin FE, Jacques NA, Hunter N. Determination of bacterial load by real-time PCR using a broad-range (universal) probe and primers set. Microbiology. 2002 Jan;148(Pt 1):257-66.

14. Slots J, Ashimoto A, Flynn MJ, Li G, Chen C. Detection of putative periodontal pathogens in subgingival specimens by $16 \mathrm{~S}$ ribosomal DNA amplification with the polymerase chain reaction. Clin Infect Dis. 1995 Jun;20(Suppl 2):S304-7.

15. Bogen G, Slots J. Black-pigmented anaerobic rods in closed periapical lesions. Int Endod J. 1999 May;32(3):204-10.

16. Xia T, Baumgartner JC, David LL. Isolation and identification of Prevotella tannerae from endodontic infections. Oral Microbiol Immunol. 2000 Aug;15(4):273-5.

17. Giraud-Morin C, Madinier I, Fosse T. Sequence analysis of cfxA2-like $\beta$-lactamases in Prevotella species. J Antimicrob Chemother. 2003 May;51(5):1293-6.

18. He J, Huang W, Pan Z, Cui H, Qi G, Zhou X, et al. Quantitative analysis of microbiota in saliva, supragingival, and subgingival plaque of Chinese adults with chronic periodontitis. Clin Oral Investig. 2012 Dec;16(6):1579-88.

19. Teles FR, Teles RP, Uzel NG, Song XQ, Torresyap G, Socransky SS, et al. Early microbial succession in redeveloping dental biofilms in periodontal health and disease. J Periodontal Res. 2012 Feb;47(1):95-104.

20. Fosse T, Madinier I, Hitzig C, Charbit Y. Prevalence of beta-lactamase-producing strains among 149 anaerobic gram-negative rods isolated from periodontal pockets. Oral Microbiol Immunol. 1999 Dec;14(6):352-7.

21. Handal T, Olsen I, Walker CB, Caugant DA. Detection and characterization of beta-lactamase genes in subgingival bacteria from patients with refractory periodontitis. FEMS Microbiol Lett. 2005 Jan 15;242(2):319-24.

22. Siqueira Junior JF, Rôças IN. Community as the unit of pathogenicity: an emerging concept as to the microbial pathogenesis of apical periodontitis. Oral Surg Oral Med Oral Pathol Oral Radiol Endod. 2009 Jun;107(6):870-8. 